Classification

Physics Abstracts

$61.16 \mathrm{Ch}$

\title{
Scanning tunneling microscopic study of passive film formed on austenitic stainless steels in ambient air and in chloride media
}

\author{
Jean Marc Olive and Vincent Vignal \\ Laboratoire de Mécanique-Physique CNRS URA No 867, Equipe Mécanique-Corrosion, Université \\ Bordeaux I, 351 cours de la Libération 33405 Talence Cedex, France
}

(Received July 4; accepted October 26, 1994)

\begin{abstract}
Résumé. - Les films passifs qui se forment spontanément sur la surface des aciers inoxydables (Fe$\mathrm{Cr}-\mathrm{Ni}$ ) jouent un rôle primordial dans le phénomène d'endommagement par Corrosion Sous Contrainte et Fatigue Corrosion. Lapparition de la corrosion localisée et la propagation des fissures est étroitement liée à leur rupture. Cette rupture résulte des effets mécaniques et électrochimique liés à la déformation plastique du substrat par modification morphologique de l'interface film-métal. Il est donc nécessaire de connaître la rhéologie de ces films pour en prévoir la rupture. Les films passifs sont constitués d'un mélange d'oxydes et d'hydroxydes et leur épaisseur ne dépasse pas 10 nanomètres. Leurs caractéristiques mécaniques ne peuvent donc pas être atteintes par la métrologie classique. Une meilleur connaissance de la structure à l'échelle atomique et notamment du caractère cristallin ou amorphe devrait permettre de mieux appréhender la réponse de ces films à des sollicitations extérieures.
\end{abstract}

\begin{abstract}
Passive films spontaneously formed on stainless steels surfaces play an essential role in Stress Corrosion Cracking and Fatigue Corrosion. Initiation of localized corrosion and propagation of cracks are linked to the rupture of these films. This rupture results on mechanical and electrochemical effects of the plastic strain of the substrate. To predict the damage of passive films, it is necessary to know their rheology. Passive films are made of a mixing up of oxides and hydroxides and their thickness doesn't exceed $10 \mathrm{~nm}$. Their mechanical features cannot be determined by classical metrology. A better knowledge of atomic structure and more particularly of the crystalline or amorphous character permits to give information on the mechanical response of these passive films to external stress.
\end{abstract}

\section{Introduction.}

It is well established that passive films formed on austenitic stainless steels play an important role in Corrosion, Stress Corrosion Cracking and Fatigue Corrosion [1]. The breakdown of passivity leads to the initiation of defects like pits, microcracks and participates to the propagation of cracks. 


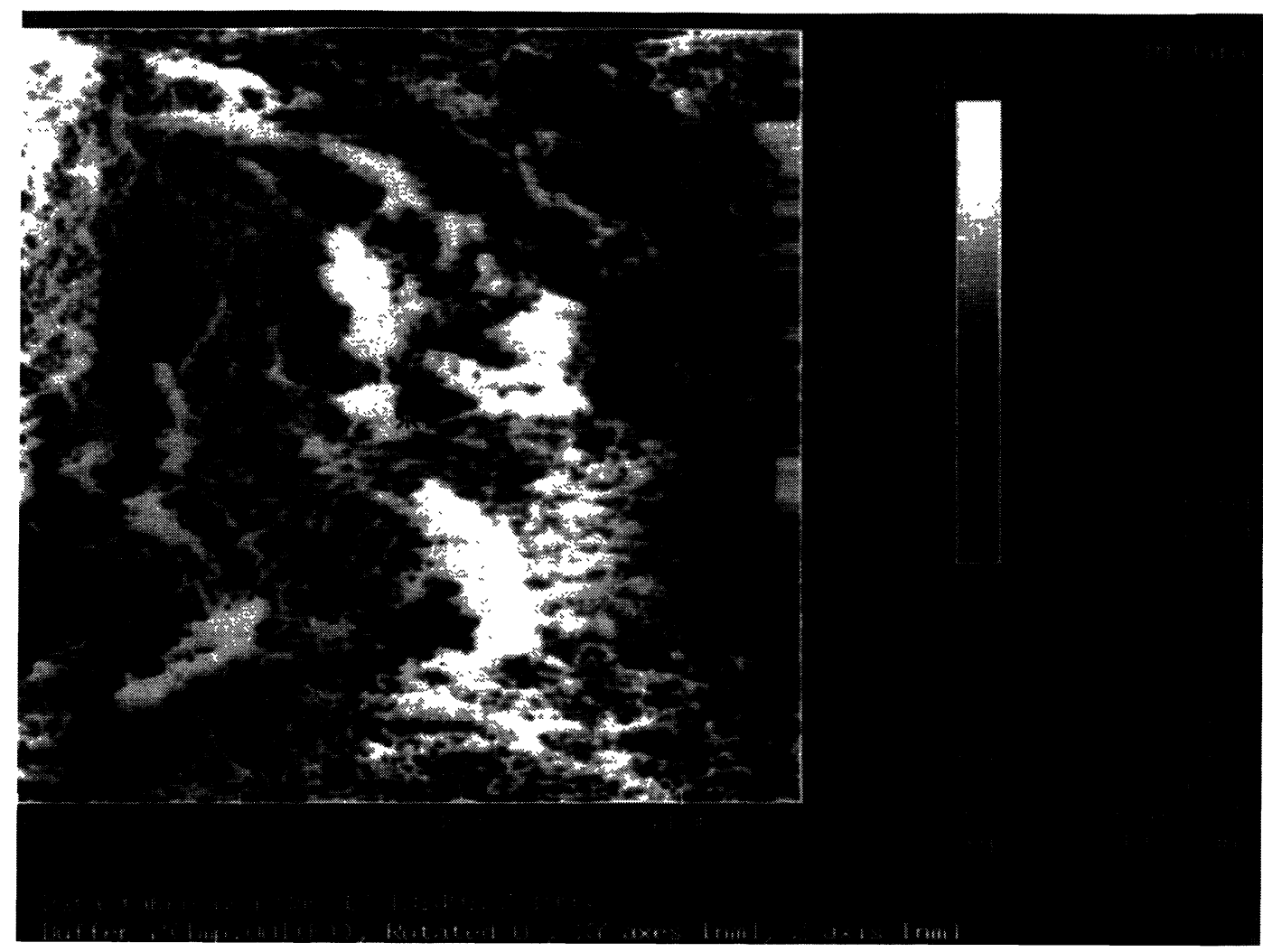

Fig. 1. - STM image of an electrochemical polishing surface of polycristalline $304 \mathrm{~L}$ sample passivated in ambiant air.

All the electrochemical processes which occur between the metal and the aqueous media depend on the behaviour of the passive film.

This film creates two interfaces; metal-film and film-electrolyte. The physical features of these interfaces and of the passive film determine the way in which the passivity breaks down. Rupture of passive films originates in several mechanisms [2, 4]; action of chloride ion, high electrostatic pressure, external strength induced by plastic strain of the substrate. In fact all of these mechanisms have to be considered as acting simultaneously in situation of stress corrosion cracking.

As far as the mechanical behaviour of passive films is concerned, Newman [5] remarked that few works have been done since the Vermilyea studies [6]. From impedance measurements, Keddam et al. [7] have compared, the anodic current transients produced by straining and abrasion. They have suggested that the mechanical behaviour of the passive film formed on iron in sulfuric acid is ductile. It can be noted that no stress corrosion cracking was observed in this system and that a relationship between the ductility of passive film and the susceptibility to the stress corrosion cracking may exist.

Earlier, Bubar et al. [8] have studied the ductility of oxyde scale and passive film. Their investigations were based on the potential dependence of the film thickness. They proposed a coefficient of ductility of $90 \%$ for a passive film formed on 304 stainless steel surface in $2 \mathrm{~N} \mathrm{Na}_{2} \mathrm{SO}_{4}$.

Grosskreutz $[9,10]$ measured fracture strain and Young modulus of 3000 Angström thickness amorphous $\mathrm{Al}_{2} \mathrm{O}_{3}$ oxide scale separated from the substrate. The mechanical behaviour was per- 


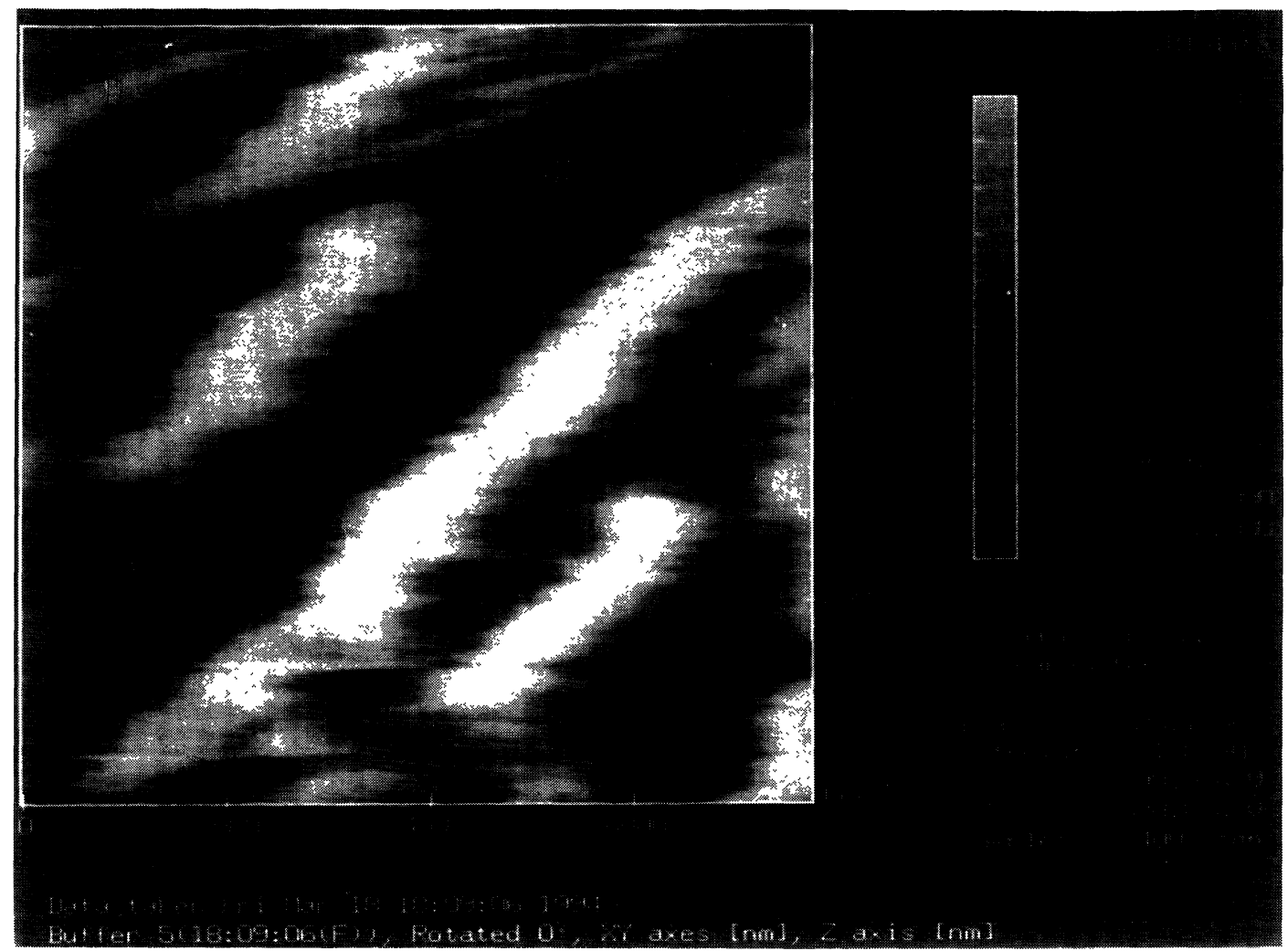

Fig. 2. - Ex situ STM image of an electrochemical polishing surfaci of polycristalline $304 \mathrm{~L}$ sample passivated in $\mathrm{MgCl}_{2}(30 \%$ weight $)$ at $117^{\circ} \mathrm{C}$.

fectly brittle. When the film was adherent to the substrate, it has been shown that, for film thickness inferior or equal to 500 Angström, the film fracture occurred on the site of slip step emergence. The fracture of thicker films occurred perpendicularly to the loading direction and independently on the substrate deformation mode.

The fracture of magnetite film formed on mild steel has been observed by Mac Carthy Harrison [11]. The rupture strain reported was about $0.8 \times 10^{-3}$. Ford [12] has measured rupture strain of oxide film from straining tests at strain rate $1.5 \times 10^{-3} \mathrm{~s}^{-1}$ and he has found $10^{-3}$. However, this value was considered too much dependent on the slip step emergence, then Ford used the values obtained by Diegle [13] which were 2 to $4 \times 10^{-3}$.

The thickness of passive film formed on the surface of stainless steels are generally between 10 and 30 Angström [14]. Thus, the classical metrology which gives the evolution of macroscopic variables as elongation and strength is inappropriate as a way of estimating the mechanical properties of passive films. During the moderately rapid straining under potentiostatic control, it has been possible to measure the strain $\varepsilon_{\mathrm{s}}$ of the sample and the corresponding stress $\sigma_{\mathrm{s}}$ which are associated with the appearance of an anodic current [15].

The deformation $\varepsilon_{\mathrm{s}}$ inferred from depassivation tests could be the intrinsic rupture strain of the passive film $\varepsilon_{\mathrm{f}}$ under the following hypothesis: (1) The strain tensor in the system film-substrate which is considered as a continuous media is homogeneous (i.e. without localized strain) (2) The. adherence between the film and the substrate is infinite. 


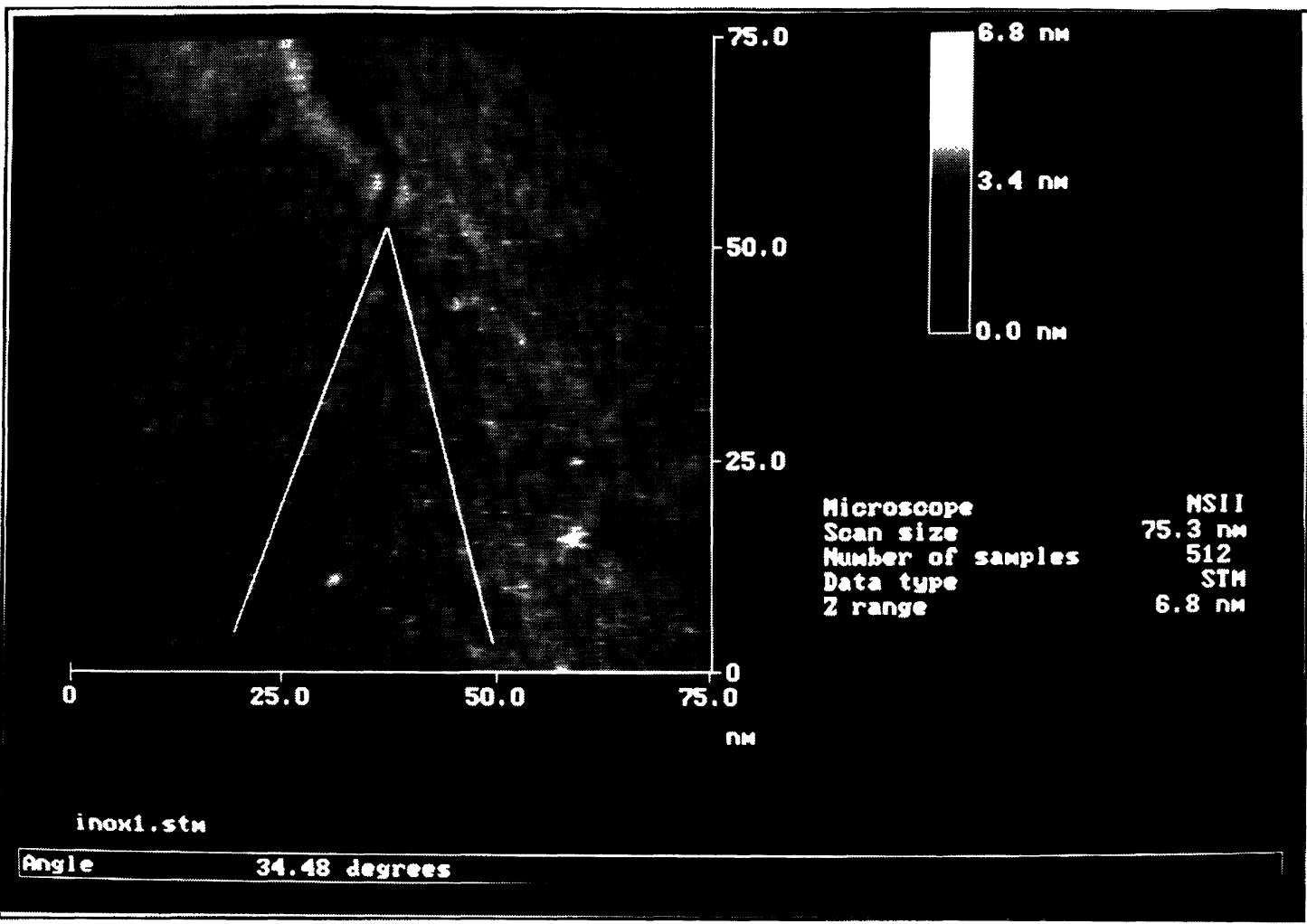

Fig. 3. - Ex situ STM image of a $304 \mathrm{~L}$ stainless steel (S.S.) surface passivated in air at room temperature. Oriented superstructures traduce an epitaxy with the substrate. There are two orientations making an angle of $34^{\circ}$ on both sides of a grain boundary.

The thickness of the film if very inferior to the size of the elementary representative volume of polycrystalline stainless steel (grain size: $100 \mu \mathrm{m}$ ). Then, the previous hypothesis are not acceptable and the film rupture is predicted to be dependent on the emergence of slip steps. The measure of the strength during moderately straining tests have shown that the depassivation current increases during the transition elastic linear-plastic deformation. Thus the intrinsic film rupture strain is higher than the elastic limit of the substrate and the deformation $\varepsilon_{\mathrm{s}}$ is the strain of the substrate at which the film rupture occurs. Therefore, the mechanical problem of the film rupture depends on the knowledge of the exterior strength induced on the film by the slip step emergence, the mechanical properties of the film and the mechanical behaviour of the interface film-substrate.

As far as the last point is concerned, Marcus et al. [16] have observed the passive film formed on Ni-Mo alloy in 0.05 M sulphuric acid solution. Static displacements of about $0.1 \AA$ have been detected on the first atomic layer of the substrate in contact with the film. The authors explain this phenomenon by the possible strain induced by the film in the substrate or by the presence of a high concentration of vacancies $(1 \%)$ at the interface film-substrate. This concentration of vacancies makes the adherence of the film on the substrate lower, adherence beeing one of the main mechanical parameter of the film rupture $[15,18]$.

Informations about composition and shape of passive film formed on austenitic stainless steel in 


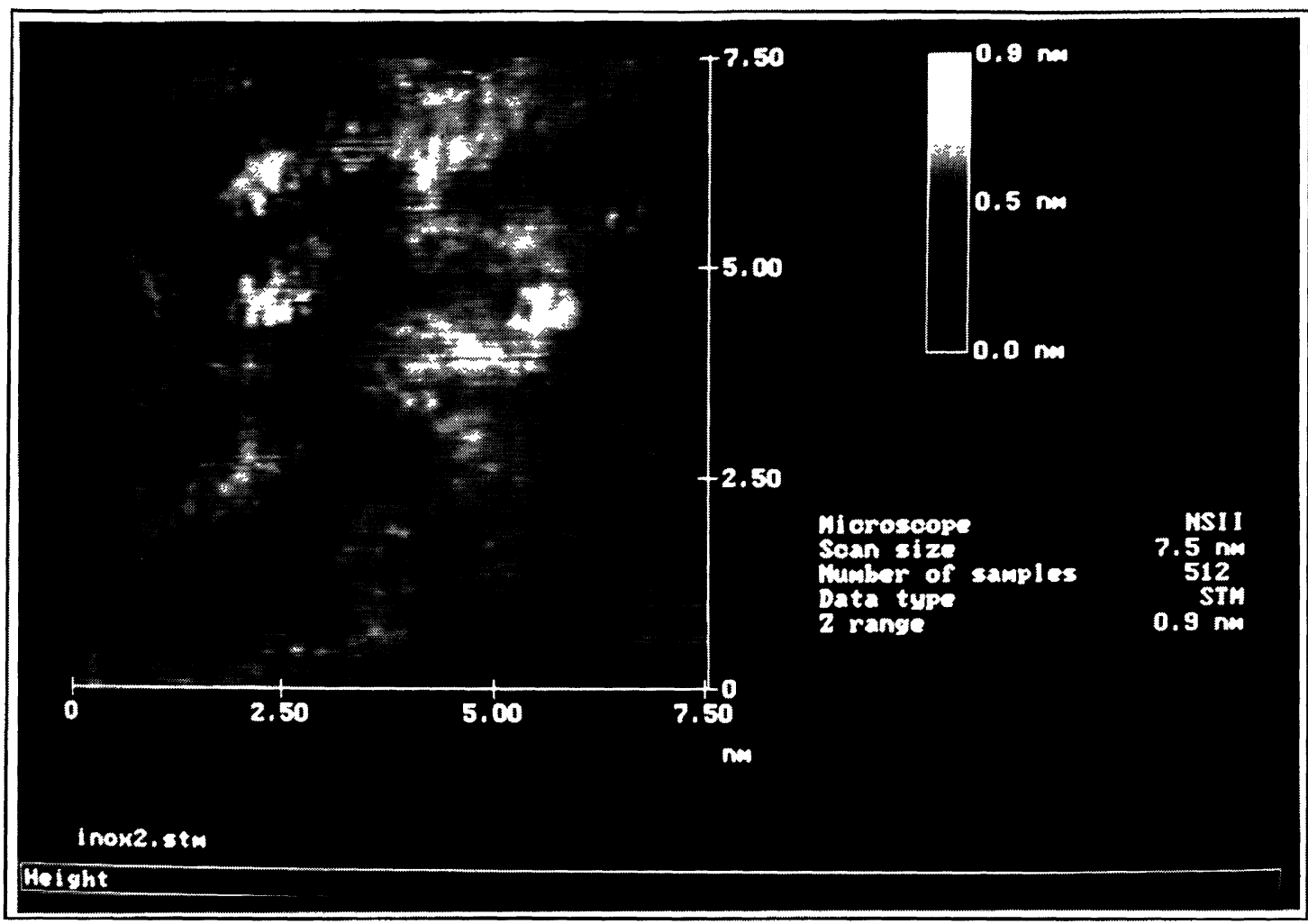

Fig. 4. - Atomic resolution ex situ STM image of a $304 \mathrm{~L}$ stainless steel passivated in air at $20^{\circ} \mathrm{C}$. Detail of an oriented superstructure showed in figure 3 at $75 \mathrm{~nm}$ scale. At 7:5.nm scale, clusters of atoms which form the superstructure are weakly ordered.

acidic media have been obtained by XPS [17]. A layered model of passive film has been proposed. Each layer is composed of different oxides and hydroxides of iron and chromium. The mechanical behaviour this type of film is the one of a multilayered material.

The aim of this study is to show how the use of STM can permit to give information about atomic structure of passive film. These informations are interpreted according to mechanical behaviour, an amorphous film beeing more ductile and then more protective than a cristallized one.

\section{Experimental.}

The Scanning Tunneling Microscope (S.T.M.) used in these experiments was a Nanoscope II instrument. To minimize acoustic, mechanical, electromagnetic vibrations and thermal changes, the microscope was situated on a vibration isolation table in a white room. All the images presented here were obtained in air and in the constant current mode, with a positive bias voltage (in the range of $20-40 \mathrm{mV}$ ) and setpoint currents between 1 and $5 \mathrm{nA}$. The residual current measured with the tip far from the substrate was approximately equal to $0.1 \mathrm{nA}$. Tips used in these studies were prepared in our laboratory by electrochemical etching of tungsten wires and then observed in Scanning Electron Microscope (S.E.M.). Moreover, to avoid loss of image quality, they were occasionally changed. 


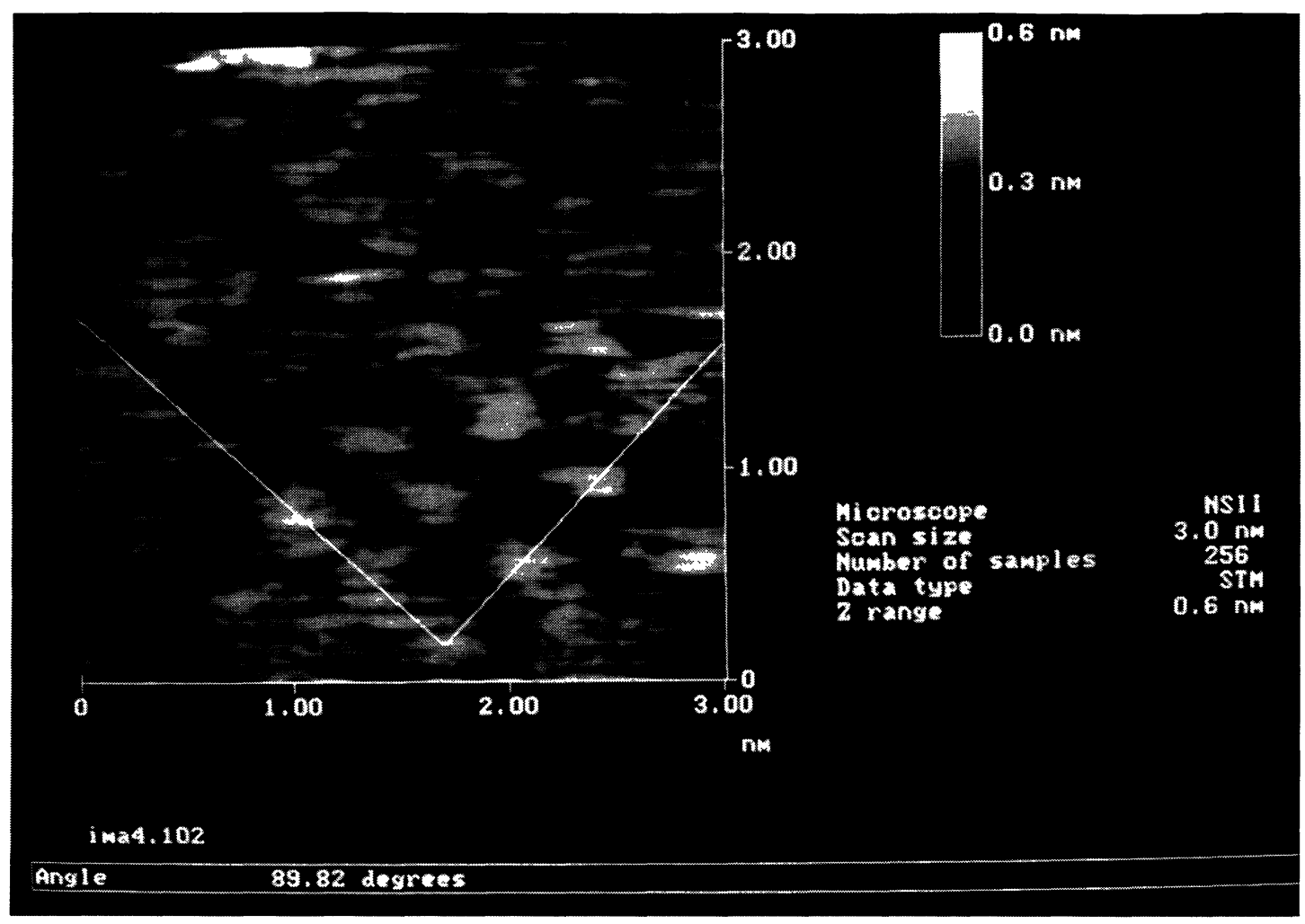

Fig. 5. - Atomic resolution of a $304 \mathrm{~L}$ stainless steel passivated in air at $20^{\circ} \mathrm{C}$ (experimental conditions: $I_{\mathrm{t}}=1 \mathrm{nA}, V_{\mathrm{t}}=20 \mathrm{mV}$ ). The atomic structure should correspond to $\mathrm{FeO}$ (lattice constant $a=4.3 \AA$, cubic) or $\mathrm{CrO}_{2}(a=4.41 \AA$, tetragonal).

The materials observed were either a $304 \mathrm{~L}$ austenitic stainless steel or a $316 \mathrm{~L}$ austenitic steel. All the samples are polycristalline, the grains are oriented at ramdom and the average grain size is $100 \mu \mathrm{m}$. The chemical composition (wt \%) of $304 \mathrm{~L}$ stainless steel used is: C: $0.021, \mathrm{Cr}: 18.18$, Ni: 10.07, Mo: 0, Si: $0.066, \mathrm{Mn}: 1.46$, S: 0.007 , P: 0.026 . The chemical composition (wt \%) of 316L stainless steel used is: C: 0.022, Cr: 17.05, Ni: 11.15, Mo: 2.17, Si: 0.53, Mn: 1.43, S: 0.013, P: 0.025 . First, samples $(10 \times 10 \times 2 \mathrm{~mm})$ were mechanically polished with succesive grades of emery paper and smoothed with different grades of diamond paste $(6 \mu \mathrm{m}, 3 \mu \mathrm{m}, 0,25 \mu \mathrm{m})$. Then, electrochemical polishing in $90 \%$ Butoxyethanol $+10 \%$ perchloric acid for 1 hour following by an etching for 30 seconds in a acid bath (20\% nitric acid $+10 \%$ hydrofluoric acid $+70 \%$ water) were performed. Between each treatment, samples were rinsed with alcohol and distilled water. The oxide layer was formed either in air at room temperature or in a $30 \%$ aqueous $\mathrm{MgCl}_{2}$ solution, at $117^{\circ} \mathrm{C}$. According to these operations, atomic resolution was obtained and images were stable enough.

\section{Results and discussion.}

Rougthness of the electrochemical etched surfaces and passivated in ambient air which are bright mirror finished were evaluated with long scans (head D) of $7000 \mathrm{~nm}$. The image in figure 1 in- 


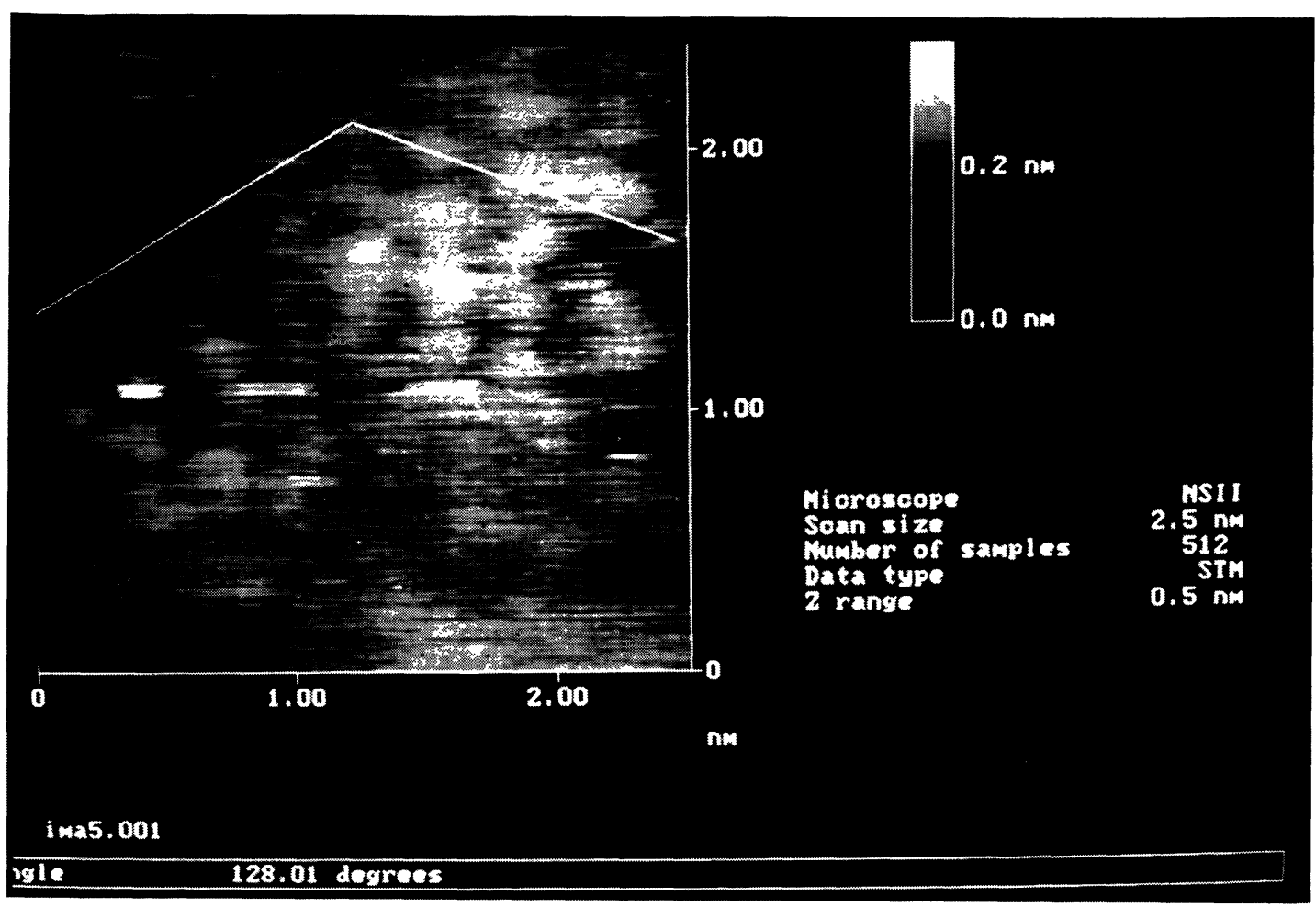

Fig. 6. - Ex situ STM image at atomic scale of a $304 \mathrm{~L}$ stainless steel passivated in air at $20^{\circ} \mathrm{C}$. Rhombohedral structures are shown (lattice constant $a=3.2 \AA, 2 \alpha=120^{\circ}$ ).

dicates that the highest defect height is $6.2 \mathrm{~nm}$. Different morphologies of defects can be seen such as: bright river lines of about $4 \mu \mathrm{m}$ length which do not have particular orientation and large clusters of several sizes (maximum $2 \mathrm{~nm}$ ). It can be noted the presence of very smooth zones ( $1.5 \mu \mathrm{m} \times 1.5 \mu \mathrm{m}$ on the left hand of the image) in which the difference of level does not exceed $2 \mathrm{~nm}$. The same scannings were performed on a surface passivated at open circuit potential in $\mathrm{MgCl}_{2}$ solution (30\% weight) at $117{ }^{\circ} \mathrm{C}$. The image shown in figure 2 was obtained ex situ after immersion of 15 minutes. A very important corrugation associated with large bright oriented bands is observed. Corrugation amplitude is $120 \mathrm{~nm}$ and the period near of $1500 \mathrm{~nm}$. The bright bands seem to be discontinuous forming lengthened small islands.

Thus, the passivation in hot chloride media leads to the appearence of a high and oriented relief. This can be attributable to anisotropic growth of passive film or anisotropic localized anodic dissolution or the both. Several mechanisms of corrugation formation can be proposed:

- Assuming that the corrugations represent thickness variations of the passive film, the substrate surface remaining smooth, the composition of the passive film should vary periodically along the surface. As it has been mentionned earlier in this paper, passive film are formed of a mixing of different metallic oxides. Several shape of passive film with different composition should be formed with their own growth kinetic and maximum thikness, forming lengthened small islands. In this case, the local thikness of the passive film would reach $120 \mathrm{~nm}$. This value is very high regarding the thickness obtained on the same system by AUGER spectroscopy which gave about $10 \mathrm{~nm}$ [19]. If the composition of passive film is assumed to be uniform, the corrugation should 


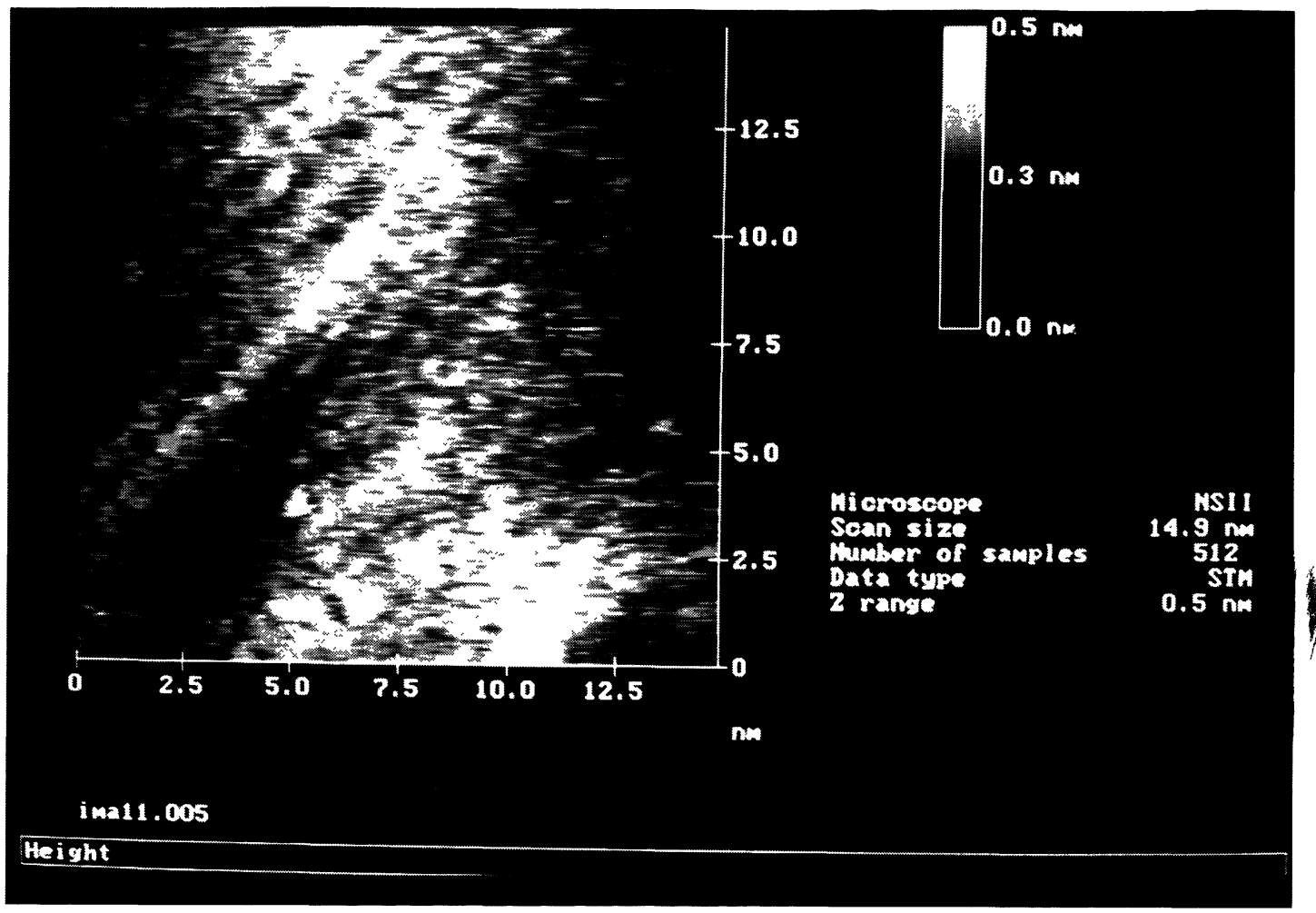

Fig. 7. - Ex situ STM image of a $304 \mathrm{~L}$ stainless steel passivated in $\mathrm{MgCl}_{2}$ at $117^{\circ} \mathrm{C}$. Oriented superstructure.

be induced by the mechanism of germination and the growth of the different oxides, a corrugated external surface being then the more stable morphology.

- An other possible mechanism is based on the anisotropy and on the localization of the corrosion processes. The establishment of the passivaty state schematically consists of the mixing up of anodic dissolution and formation of oxides. Anisotropic anodic dissolution depends on the cristallographic orientation of the substrate. It is previsible that dissolution occurs favourably along traces of $\{111\}$ planes. The localization of the anodic dissolution implies that all $\{111\}$ planes traces are not attacked simultaneously (general dissolution) but only a few number of them. This leads to a periodic preferential anodic dissolution on oriented axes ( $\{111\}$ planes traces). The subsequent growth of passive film (different from the ones formed in the ambient air before the immersion) should be then oriented along the same direction.

The relationship between corrugation orientation and cristallographic orientation of the substrate has been shown by imaging the proximity of a grain boundary.

A grain boundary on the surface of a $304 \mathrm{~L}$ passivated in air can be seen in figure 3 . Oriented linear superstructure appear on important areas on both sides of the boundary making an angle of $34^{\circ}$. This superstructure consists of very thin corrugations which are formed by lengthened small islands. The corrugation period is about $3 \mathrm{~nm}$. This situation traduces an epitaxy with the substrate since the corrugation direction is associated with the grain cristallographic orientations of the polycristal. On the right side of the grain boundary, a lower scan of $7.5 \mathrm{~nm}$ has been obtained with atomic resolution (Fig. 4). This image shows that lendgthened small islands of figure 3 are 


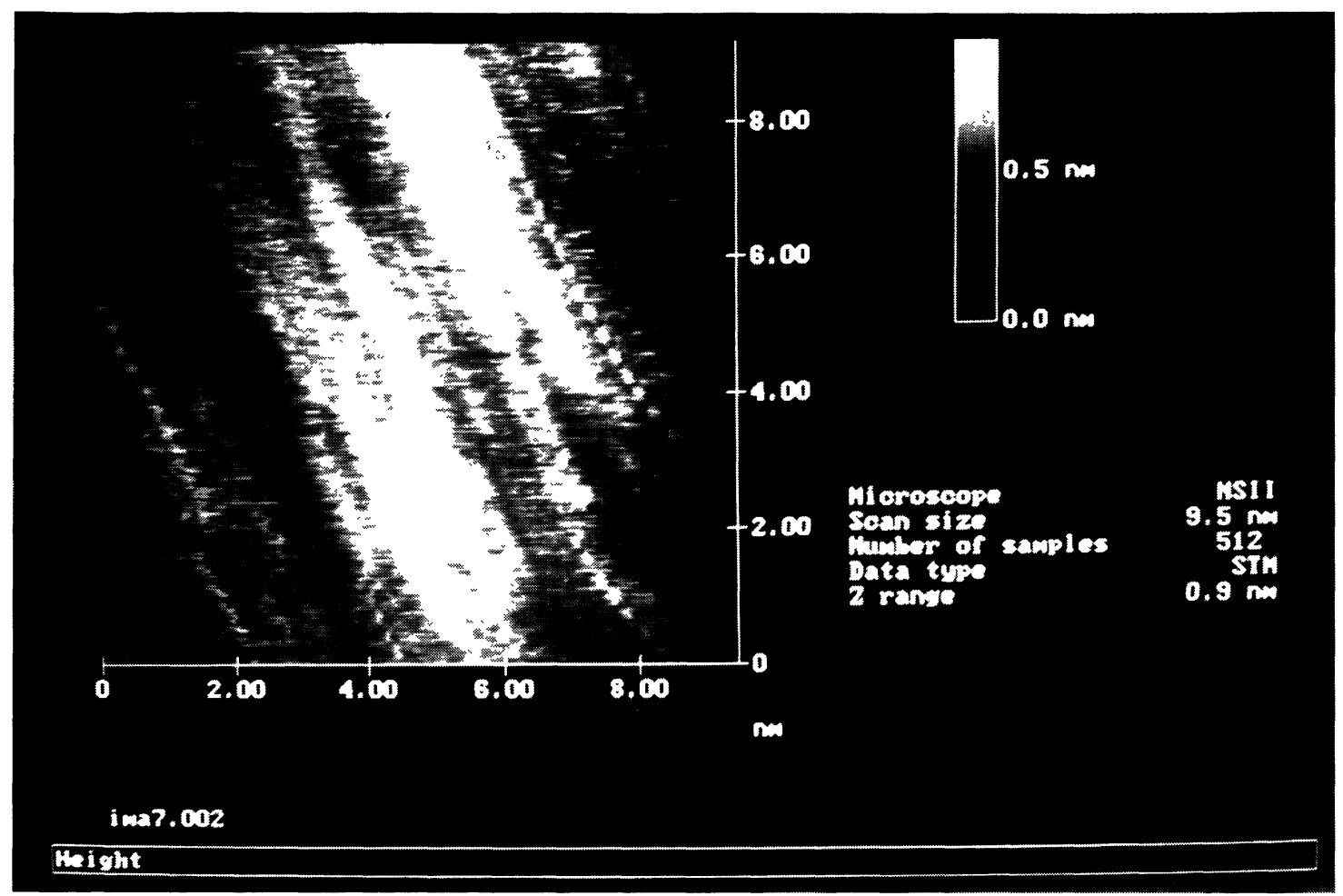

Fig. 8. - Ex situ STM image at atomic scale of a 316 L austenitic steel passivated in air at room temperature $\left(I_{\mathrm{t}}=4.2 \mathrm{nA}, V_{\mathrm{t}}=32 \mathrm{mV}\right)$. Important oriented rows of atoms indicating the existence of an order in a long distance.

composed of an alignment of clusters containing about twenty visible atoms. A cristallographic order cannot be identified in these clusters.

Atomic structure of passive films formed in air at $20^{\circ} \mathrm{C}$ on $304 \mathrm{~L} \mathrm{SS}$ was clearly observed on several images. Figure 5 shows that atoms of the oxide matrix are ordered in two directions making an angle about of $90^{\circ}$. Besides, the lattice constant measured is approximately $4.64 \AA$. Thus, we can assume that this crystallographic structure could correspond to cubic or tetragonal systems. Two oxides have a struct ${ }_{2}$ re near of these: $\mathrm{FeO}$ crystallizes in cubic system with a lattice constant $a=4.3 \AA$ and $\mathrm{CrO}_{2}$ crystallizes in tetragonal system with the lattice constant equal to $4.41 \AA$. In the image illustrated figure 6 , atoms are always ordered in two directions making an angle of $120^{\circ}$ (rhombohedral arrangment) and the lattice constant is equal to $3.2 \AA$. $\beta$-NiO crystallizes in this system but this oxide is generally obtained at $275^{\circ} \mathrm{C}$. $\mathrm{Cr}_{2} \mathrm{O}_{3}$ have rhombohedral structure too, but a lattice constant of about $5.36 \AA$ which is much higher than the one observed.

Ex situ observations of surfaces of polycristalline $304 \mathrm{~L}$ passivated in $\mathrm{MgCl}_{2}$ solution at $117^{\circ} \mathrm{C}$ have been realized at low scans. Image in figure 7 shows well-oriented superstructure forming corrugation of period $1 \mathrm{~nm}$. Just like in larger scans (Fig. 3), an order exist at $15 \mathrm{~nm}$ scan. This denotes the high fractal character of passive films.

At this stage of the study, it is very difficult to identify the origine of these superstuctures since it doesn't exist structural models of passive films as a mixing up of oxides and hydroxides. 
Few experiments have been made with a $316 \mathrm{~L}$ SS passivated in ambient air. An image shown in figure 8 proove that an order exist in a long scale in the oxide. So, we can suppose that the passive film formed on $316 \mathrm{~L}$ in air is at least partially crystallized and certainly a strong epitaxy exists with the substrate.

\section{Concluding remarks.}

These first observations could lead to make important remarks on the structure of the external part of the passive film formed on austenitic steels surfaces under different conditions:

- All these images proove the existence of an order on a significant distance suggesting that the passive film is at least partially crystallized. Even if no order seem to exist at atomic scale, for longer scans, corrugations denotes a strong epitaxy relation between the substrate and the supercial film either at atomic scale or at long scans.

- Under the same experimental conditions and for the same austenitic steel, different crystallographic systems are observed on stainless steel surface (cubic, tetragonal, rhombohedral). This constatation proove that several oxides can be present in the external layer of the passive film, even if at the present time we cannot precisely identify these oxides. Therefore, more or less important amorphous zones should exist as transition zones between these crystallographic structures.

- The strong cristallized character of the passive films suggests that their mechanical behavior is much more brittle than ductile.

These first observations were not realized in satisfactory experimental conditions. At present, we attempt to control electrochemical parameters to produce a more homogeneous film with less contamination. In this way, we use $316 \mathrm{~L}$ oriented single crystal and the Electrochemical Cellule STM (ECSTM) to operate in situ. The experiments are pertormed in a glooves box under inert atmosphere in order to control humidity and oxygen content.

\section{Acknowledgments.}

The authors would like to express their gratitude to Dr. H. Saadaoui, C. Daulan and Pr. J.C. Roux for their assistance with the STM experiment and for stimulating discussions.

\section{References}

[1] Diegle R.B., Boyd W.K., Slow strain technique, ASTM STP 665, G.M. Ugiansky and J.H. Payer Eds. (1979) 26.

[2] Galvele J.R., "Passivity of metals", R.P. Frankhental and J. Kruger Eds., The Electrochemical Society (1978) 285.

[3] Janik-Czachor M., J. Electrochem. Soc. 128 (1981) 513.

[4] Kruger J., Int. Met. Rev. 33 (1988) 113.

[5] Newman R.C. in "Embrittlement by localized crack environment", R.P. Gangloff Ed., AIME (1984) 291.

[6] Diegle R.B. and Vermilyea D.A., Corrosion 32 (1976) 411.

[7] Keddam M., Oltra R., Colson J.C. and Desestret A., Corros. Sci. 23 (1983) 441.

[8] Bubar S.F. and Vermilyea D.A., J. Electrochem. Soc 114 (1967) 882.

[9] Grosskreutz J.C., J. Electrochem.Soc. 117 (1970) 940. 
[10] Grosskreutz J., J. Electrochem. Soc. 16 (1969) 1232.

[11] Mc Carthy Harrison H.A., Corros. Sci. 14 (1974) 469.

[12] Ford F.P., EPRI report, NP 2589 (1982).

[13] Diegle R.A. and Vermilyea D.A., Corrosion 32 (1976) 411.

[14] Marcus P., “Corrosion Sous Contrainte, Phénoménologie et Mécanismes”, D. Desjardins et R. Oltra, Editions de Physique (1990) 101.

[15] Olive J.M., Desjardins D., in “Corrosion Deformation interactions”, T. Magnin and J.M. Gras Eds. (1993) 755.

[16] Marcus P., J. Electrochem. Soc. 135 (1988) 2706.

[17] De Vito E. and Marcus P., Surf. Interf. anal. 19 (1992) 403.

[18] Olive J.M., Vignal V., 7th inter. Symp. on Passivity, Clausthal, Germany, (August 1994) accepted.

[19] Sarrazin C., Olive J.M., Karray R., Desjardins D., unpublished results (1993). 